\section{Influence of Photoperiod Duration and Phloem Disruption through Scoring on Growth, Disease Symptoms, and Bacterial Titer in Citrus Graft Inoculated with Candidatus Liberibacter asiaticus}

Ed Stover ${ }^{1}$ and Robert G. Shatters, Jr. U.S. Horticultural Research Laboratory, U.S. Department of Agriculture, Agricultural Research Service, 2001 South Rock Road, Fort Pierce, FL 34945

Barrett Gruber and Prem Kumar
Indian River Research and Education Center, 2199 South Rock Road,
University of Florida, Fort Pierce, FL 34945

Gloria A. Moore

Horticultural Sciences Department, 1111 Fifield Hall, Box 110690, University of Florida, Gainesville, FL 32611

Additional index words. citrus greening, disease resistance, HLB, huanglongbing, disease tolerance, stress interaction, SPAD

Abstract. Plants inoculated with the huanglongbing (HLB)-associated bacterium, Candidatus Liberibacter asiaticus (CLas) typically must be monitored for $8-10$ months to identify differences in susceptibility between genotypes. Continuous light is reported to accelerate development of HLB symptoms and field observations suggest that trees girdled by tags or tree ties showed greater symptoms. Therefore, an experiment was conducted assessing HLB susceptibility as influenced by light/dark periods of 12 hours: 12 hours and 24 hours: 0 hours, in combination with scoring tree trunks to disrupt phloem. Sixty trees of each of three citrus genotypes ('Kuharske', previously shown to be HLB resistant; rough lemon, previously shown to be HLB tolerant; and 'Valencia', highly HLB susceptible) were bud grafted using two CLas-infected buds (rough lemon and citron) per tree on 26 Mar. 2012, and were placed in controlled growth rooms (one 12 hour light: 12 hour dark and one constant light) on 4 June 2012. Ten trees of each genotype in each growth room were scored $10 \mathrm{~cm}$ above the soil (cutting through the bark but not the wood) with a knife on 18 July 2012 and the scoring was repeated at the same scoring wounds on 30 Aug. 2012. Trees were removed from growth rooms on 12 Dec. 2012 and subsequently maintained in a greenhouse. At two to three month intervals between June 2012 and May 2013, HLB symptoms and stem diameter at $5 \mathrm{~cm}$ above the soil were assessed, and three leaves per tree were collected for quantitative polymerase chain reaction (qPCR) determination of CLas titer. Six months after inoculation and 3 months following imposition of treatments, the 'Valencia' scored in the 12 hour light: 12 hour dark regime, the 'Valencia' non scored trees in 24 hours of light and the 'Kuharske' scored trees in $\mathbf{2 4}$ hours of light displayed higher CLas titers than most other trees. After an additional two months, both scored and non-scored trees of all three genotypes in 24 hours of light had significantly elevated CLas titers compared with trees in 12 hour light: 12 hour dark regime, but within most treatments all three genotypes had titers which were not statistically different from each other. Growth of 'Kuharske' and rough lemon was enhanced; whereas 'Valencia' growth was reduced when graft-inoculated plants were maintained in continuous light. Scoring enhanced early CLas development in 'Kuharske' when combined with continuous light, had no effect in rough lemon, and showed inconsistent effects in 'Valencia'. Although continuous lighting enhanced disease progression, it did not reveal differences in HLB susceptibility.

Huanglongbing is devastating the Florida citrus industry and is considered as the greatest threat to global citrus production (Bové, 2006). In the United States, CLas is recognized as the pathogen causing HLB, and is vectored by the Asian citrus psyllid (ACP),
$80 \%$ of Florida citrus trees are infected (Singerman and Useche, 2015) and overall production is at the lowest level in 50 years. HLB is continuing to spread in Texas, and several infected dooryard trees have been reported in California (Western Farm Press, 2016).

Development of citrus cultivars resistant to HLB is the best long-term solution for control of this disease where it is endemic. Some resistance or field tolerance to HLB within citrus and citrus relatives has been described outside the United States (Bhagabati, 1993; Fraser and Singh, 1970; Halbert and Manjunath, 2004; Miyakawa, 1980; Miyakawa and Yuan, 1990; Nariani, 1981; Sharma et al., 2004). Compared with other tested cultivars within individual experiments, lower susceptibility to HLB associated with CLas has been reported for limes (Lange et al., 1985; Schwarz et al., 1973; Shokrollah et al., 2009), pummelos (Koizumi et al., 1997; Schwarz et al., 1973), lemons (Cheema et al., 1982; Nariani, 1981; Schwarz et al., 1973), some mandarin types (e.g., 'Ladu' and 'Som Pan' in Thailand; Koizumi et al., 1997), and various noncultivated Citrus or related genera.

The citrus relative Poncirus trifoliata has been recognized as a potential source of resistance to HLB. Poncirus and its hybrid, 'Carrizo' citrange, developed less severe HLB symptoms and among the lowest titers of CLas of the genotypes evaluated in a greenhouse study shortly after HLB arrived in Florida (Folimonova et al., 2009). A trial of 85 seedling populations from accessions of Citrus and citrus relatives (provided as seeds from the U.S. National Clonal Germplasm Repository in Riverside, CA) has been underway for 6 years in an orchard with intense HLB and ACP pressure in Ft. Pierce, FL. Poncirus, Microcitrus, and Eremocitrus are among the few genotypes in the citrus gene pool that continue to show resistance to HLB (Ramadugu et al., 2016). In addition, there are several research programs attempting to generate HLB resistance in citrus using biotechnology (Dutt et al., 2015; Hao et al., 2016).

Unfortunately, it is difficult to quickly and efficiently screen for resistance to HLB. It typically takes 8-10 months to observe a high level of CLas infection even in highly susceptible sweet orange following graft inoculation or exposure to CLas-infected ACP. There are reports that continuous light accelerated the development of HLB symptoms, and it was proposed that this condition exacerbated the abnormal accumulation of starch associated with HLB (Folimonova et al., 2009). Field observations have indicated that trees mechanically girdled by tags or tree ties sometimes showed greater HLB symptoms, and again, such girdling might further enhance starch accumulation. Therefore, this study was initiated to determine if use of continuous lighting or phloem disruption from scoring (like girdling without removal of a bark strip) would enhance the efficiency of evaluating HLB susceptibility, following 
inoculation of three citrus cultivars known to vary in HLB response.

\section{Materials and Methods}

All experimental trees were maintained in a greenhouse at the U.S. Horticultural Research Laboratory in Ft. Pierce, FL, unless otherwise noted.

Graft inoculations. The original inoculum of CLas was from an infected 'Lisbon' lemon (C. limon) from a commercial grove near $\mathrm{Ft}$. Pierce, FL (Albrecht and Bowman, 2008), which has been used extensively in experiments, with infected trees sustained through serial graft transmission. Trees of rough lemon (Citrus jambhiri, nucellar seedlings) and citron (Citus medica, cultivar Mhac Nao from rooted cuttings) were graft inoculated on 20 Oct. 2010 with CLas using infected 'Valencia' (Citrus sinensis) budwood at three buds per tree. These rough lemon and citron trees developed distinctive HLB mottling and high CLas titer and provided materials for graft inoculations for the experiment reported here (Stover et al., 2016a). Sixty trees each of 'Valencia' (budded onto rough lemon nucellar seedlings), nucellar seedlings of rough lemon, and nucellar seedlings of 'Kuharske' (C. sinensis $\times P$. trifoliata) were graft inoculated on 26 Mar. 2012 with CLas using a combination of infected rough lemon and citron budwood at two buds per tree. Buds were cut from the branches clearly showing blotchy mottle symptoms, and buds with attached leaves were randomly assigned to target trees, with associated leaves of most buds having a cycle threshold $(\mathrm{Ct})$ value of 22-25. All trees received at least one bud from rough lemon. Target trees were $4-8 \mathrm{~mm}$ in diameter when bud inoculated and 0.5$0.9 \mathrm{~m}$ in height. Thirteen trees (all but one were rough lemon) were rebudded in the same manner on 30 May 2012 when both inoculum buds were observed to be dead on 1 May 2012.

Illumination and scoring treatments. Trees were placed in walk-in growth rooms on 4 June 2012 (Environmental Growth Chambers, GR Series with TC-2 Microcontrollers, Chagrin Falls, $\mathrm{OH}$; one at $12 \mathrm{~h}$ light: $12 \mathrm{~h}$ dark periods and one with constant light. Both rooms were $16 \mathrm{~h}$ at $30{ }^{\circ} \mathrm{C}$ and $8 \mathrm{~h}$ at $25^{\circ} \mathrm{C}$ ). Ten trees of each genotype in each

\footnotetext{
Received for publication 24 June 2016. Accepted for publication 17 Aug. 2016.

This project was funded in part through USDA/ APHIS.

We thank Regina Tracy, Belkis Diego, Ashley Witkowski, and Diane Helseth for their technical assistance.

USDA is an equal opportunity provider and employer.

Mention of trade names or commercial products in this article is solely for the purpose of providing specific information and does not imply recommendation or endorsement by the U.S. Department of Agriculture.

${ }^{1}$ Corresponding author. E-mail: ed.stover@ars.usda. gov.
}

growth room were scored (through the bark but not the wood) with a knife on 18 July 2012 and the scoring was repeated on the same trees at the same scoring wounds on 30 Aug. 2012. Trees were removed from growth rooms on 12 Dec. 2012 and subsequently maintained in a greenhouse with ambient lighting and temperatures ranging from 15.6 to $30.6{ }^{\circ} \mathrm{C}$ (mean $22.8^{\circ} \mathrm{C}$ ).

Data collection. At 2 to 3 month intervals between June 2012 and May 2013, HLB symptoms and stem diameter at $5 \mathrm{~cm}$ above the soil were assessed, and three leaves per tree were collected and pooled for $\mathrm{qPCR}$ determination of CLas titers. Presence of blotchy mottle was visually estimated for each tree as the percentage of total canopy leaf area affected. During 29-31 Oct. 2012, chlorophyll levels were measured using a SPAD meter (Konica Minolta Inc., Tokyo, Japan) on all nongirdled trees. Three of the most symptomatic leaves were measured on each tree and the three chlorophyll measurements were then averaged.

Determination of CLas titer. All leaf samples were stored at $-20{ }^{\circ} \mathrm{C}$ until processed. For each tree, the lower $2 \mathrm{~cm}$ from the leaf petiole base into the midrib were macerated in a Fast Prep 24 (MP Biomedicals, Santa Ana, CA) with DNA extracted from $200 \mathrm{mg}$ of macerated tissue using cetyl trimethylammonium bromide (CTAB) extraction followed by column clean up and concentration (Genesee Scientific, San Diego, CA). Each sample was assayed for CLas and citrus dehydrin via $\mathrm{qPCR}$ using an ABI 7500 thermocycler (Applied Biosystems, Foster City, CA). Each $25 \mu \mathrm{L}$ qPCR reaction was conducted using $100 \mathrm{ng}$ of DNA template with primers specific to 16s rDNA for CLas detection (USHRL-CL1-L 5'-CTTACCAGCCCTTGACATGTATAGG-3' and USHRL-CL1-R 5'-TCCCTATAAAG TACCCAACATCTAGGTAAA-3' ) or Citrus dehydrin (CD-L 5'-TGAGTACGAGCCGA GTGTTG-3' and CD-R 5'-AAAACTTCAC CGATCCACCAG-3'). Citrus dehydrin was used as reference control to verify DNA quality and PCR amplification. The master mix consisted of Promega (Madison, WI) GoTaq qPCR with BRYT Green and $0.2 \mu \mathrm{M}$ of each primer using cycle parameters of 2 min $95^{\circ} \mathrm{C}$ start, 40 cycles of $15 \mathrm{~s}$ at $95^{\circ} \mathrm{C}$, $20 \mathrm{~s}$ at $60{ }^{\circ} \mathrm{C}$, and $20 \mathrm{~s}$ at $72{ }^{\circ} \mathrm{C}$, with a melt curve analysis (to verify product identity). From $\mathrm{Ct}$ values, numbers of CLas genomes were calculated per ng DNA extracted, based on previously published laboratory analyses (Stover et al., 2015).

Statistical analyses. All data including qPCR results (analyzed as $\mathrm{Ct}$ ) were assessed using the nonparametric Kruskal-Wallis test using Statistical Analysis Software version 9.4 (SAS Institute Inc., Cary, NC). Where CLas was found to be nondetectable, a $\mathrm{Ct}$ value of 45 was assigned for use in the analyses (which is less than one copy per sample analyzed). Regressions of SPAD readings vs. CLas Ct in Nov. 2012 were conducted using Excel (Microsoft, Redmond, WA).

\section{Results and Discussion}

Development of CLas titer. The main effect of genotype, averaged across all treatments, was significant at three of four dates where titers were compared, with 'Kuharske' showing the lowest titer and 'Valencia showing the highest titer (Table 1), as expected based on previous studies. The main effect of scoring was never significant and illumination averaged across genotypes and scoring was significant only in Nov. 2012, when CLas titer was significantly enhanced by continuous illumination with $\approx 150$-fold more CLas than in $12 \mathrm{~h}$ light: $12 \mathrm{~h}$ dark.

Three-way interactions of genotype/illumination/scoring revealed several interesting points (Table 1). On Sept. 2012, at 6 months after inoculation, both 'Kuharske' and 'Valencia' displayed markedly greater CLas titer in continuous illumination, except that 'Kuharske' displayed this increase only when scored, and 'Valencia' only when not scored. On Nov. 2012, at 8 months after inoculation, all genotypes displayed markedly greater CLas titer in continuous illumination compared with $12 \mathrm{~h}$ light: $12 \mathrm{~h}$ dark, whether scored or not, though 'Valencia'/ continuous illumination/scored had higher titer than 'Valencia'/continuous illumination/ not scored. Most markedly, all three genotypes had titers which were not statistically different from each other when exposed to continuous illumination and sampled at 8 months after inoculation. Rather than facilitating differentiation between HLB-susceptible and HLBresistant genotypes, exposure to continuous illumination accelerated pathogen development but compressed differences in susceptibility. With a few exceptions, differences between treatments within genotypes were few and inconsistent on Mar. 2013 and May 2013 after trees had been removed from the growth rooms and returned to ambient lighting in the greenhouse.

Development of distinctive HLB mottle. Negligible mottle was observed before Sept. 2012. 'Kuharske' trees displayed slight mottle symptoms when exposed to continuous illumination (at 6-8 months following inoculation, Sept. 2012 and Nov. 2012), which were only statistically significant when combined with scoring (Table 2). Rough lemon also displayed only minor levels of mottling with inconsistent treatment differences, but with higher mottling at $12 \mathrm{~h}$ light: $12 \mathrm{~h}$ dark vs. continuous lighting with no scoring in Nov. 2012 and Mar. 2013. 'Valencia' consistently showed the greatest numerical percentage of leaf area with mottle symptoms compared with the other genotypes. At almost every date of comparison, within 'Valencia', the greatest level of mottling was observed in trees with continuous lighting and no scoring.

SPAD assessment of chlorophyll. SPAD readings correlated with CLas titer on the one date when tested at 8 months after inoculation (Table 1). An examination of the means in Table 1 shows significant differences between SPAD readings corresponded to significant differences between CLas titer from the same 
Table 1. Cycle threshold $(\mathrm{Ct})$ values (translation into bacterial titer in footnote) for three leaf samples from each tree at each date, collected for quantitative polymerase chain reaction (qPCR) determination of titers of huanglongbing (HLB) pathogen Candidatus Liberibacter asiaticus (CLas). Sixty trees of each of three citrus genotypes ('Kuharske', previously shown to be HLB resistant; rough lemon, previously shown to be HLB tolerant; and 'Valencia', HLB susceptible) were bud grafted using two CLas-infected buds per tree on 26 Mar. 2012 and were placed in controlled growth rooms (one $12 \mathrm{~h} \mathrm{light:} 12 \mathrm{~h}$ dark and one constant light, both rooms were $16 \mathrm{~h}$ at $30^{\circ} \mathrm{C}$ and $8 \mathrm{~h}$ at $25^{\circ} \mathrm{C}$ ) on 4 June 2012 . Ten trees of each genotype in each growth room were scored with a knife on 18 July 2012 and the scoring was repeated on the same trees at the same scoring wounds on 30 Aug. 2012. Trees were removed from growth rooms on 12 Dec. 2012 and subsequently grown in a greenhouse.

\begin{tabular}{|c|c|c|c|c|c|c|c|}
\hline \multicolumn{3}{|c|}{ Three-way interaction } & \multicolumn{4}{|c|}{$\mathrm{Ct}$ for $\mathrm{CLas}^{2}$} & \multirow{2}{*}{$\frac{\text { SPAD value }}{\text { Nov. } 12}$} \\
\hline Genotype & Light & Score & Sept. 12 & Nov. 12 & Mar. 13 & May 13 & \\
\hline Kuharske & $12: 12$ & No & $37.6 \mathrm{a}$ & $32.1 \mathrm{bc}$ & $42.1 \mathrm{a}-\mathrm{c}$ & $40.9 \mathrm{a}-\mathrm{c}$ & $71.3 \mathrm{a}$ \\
\hline Rough lemon & $12: 12$ & Yes & $34.0 \mathrm{ab}$ & $36.5 \mathrm{a}$ & $44.5 \mathrm{ab}$ & $36.0 \mathrm{~b}-\mathrm{e}$ & \\
\hline Rough lemon & $12: 12$ & No & $35.8 \mathrm{a}$ & $33.5 \mathrm{ab}$ & $37.4 b-d$ & $36.7 \mathrm{bc}$ & $49.2 \mathrm{c}$ \\
\hline Rough lemon & 24 & Yes & $36.8 \mathrm{a}$ & $23.6 \mathrm{e}$ & $31.4 \mathrm{de}$ & $30.3 \mathrm{de}$ & \\
\hline Valencia & $12: 12$ & No & $33.2 \mathrm{ab}$ & $34.7 \mathrm{ab}$ & $30.8 \mathrm{e}$ & $29.6 \mathrm{e}$ & $61.0 \mathrm{~b}$ \\
\hline Valencia & 24 & Yes & $33.0 \mathrm{ab}$ & $23.2 \mathrm{e}$ & $45.0 \mathrm{a}$ & $28.7 \mathrm{e}$ & \\
\hline Valencia & 24 & No & $26.5 \mathrm{c}$ & $30.5 \mathrm{~cd}$ & $32.9 \mathrm{de}$ & $30.3 \mathrm{de}$ & $38.3 \mathrm{~d}$ \\
\hline \multicolumn{3}{|c|}{ Main effects } & \multicolumn{4}{|c|}{$\mathrm{Ct}$ for CLas } & \\
\hline Genotype & Light & Score & Sept. 12 & Nov. 12 & Mar. 13 & May 13 & \\
\hline Kuharske & & & $35.5 \mathrm{a}$ & $30.5 \mathrm{a}$ & $42.2 \mathrm{a}$ & $41.4 \mathrm{a}$ & \\
\hline & & Yes & $33.1 \mathrm{a}$ & $30.5 \mathrm{a}$ & $40.1 \mathrm{a}$ & $35.5 \mathrm{a}$ & \\
\hline & & No & $34.3 \mathrm{a}$ & $30.8 \mathrm{a}$ & $37.8 \mathrm{a}$ & $35.8 \mathrm{a}$ & \\
\hline
\end{tabular}

${ }^{\mathrm{z}} \mathrm{Ct}$ corresponds to genomes of CLas/ $\mu \mathrm{g}$ DNA as follows: $22=1,800,000 ; 26=142,000 ; 30=11,500 ; 34=930 ; 38=75$; and $42=6$. Conversion as described in Stover et al. (2015).

${ }^{y}$ Within a column and section (sections separated by horizontal lines), means followed by the same letter are not significantly different at $P \leq 0.05$.

Table 2. Percentage of leaf area showing typical huanglongbing (HLB) symptom of blotchy mottle. Sixty trees of each of three citrus genotypes ('Kuharske', previously shown to be HLB resistant; rough lemon, previously shown to be HLB tolerant; and 'Valencia', HLB susceptible) were bud grafted using two Candidatus Liberibacter asiaticus (CLas)-infected buds per tree on 26 Mar. 2012 and were placed in controlled growth rooms (one $12 \mathrm{~h} \mathrm{light:} 12 \mathrm{~h}$ dark and one constant light, both rooms were $16 \mathrm{~h}$ at $30^{\circ} \mathrm{C}$ and $8 \mathrm{~h}$ at $25^{\circ} \mathrm{C}$ ) on 4 June 2012 . Ten trees of each genotype in each growth room were scored with a knife on 18 July 2012 and the scoring was repeated on the same trees at the same scoring wounds on 30 Aug. 2012. Trees were removed from growth rooms on 12 Dec. 2012 and subsequently grown in a greenhouse.

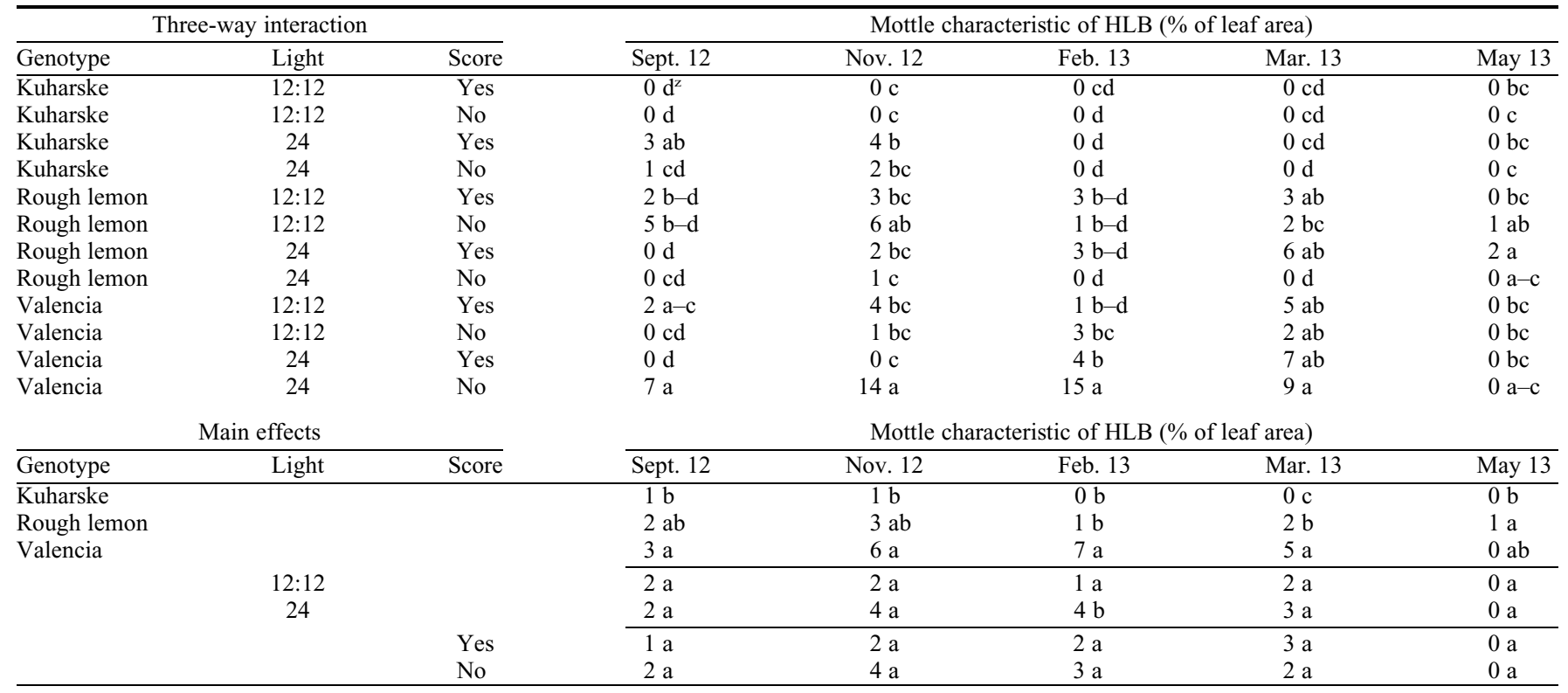

${ }^{\mathrm{z}}$ Within a column and section (sections separated by horizontal lines), means followed by the same letter are not significantly different at $P \leq 0.05$.

date. When individual tree data for SPAD and Ct were compared, the correlations were significant and positive across all three genotypes combined $(P=0.0008)$, for 'Valencia' alone $(P=0.03)$ and for rough lemon alone $(P=0.002)$ but not Kuharske alone $(P=0.12)$. However, the $r^{2}$ for regression across all genotypes is only $0.09\left(r^{2}\right.$ is 0.06 in Kuharske, 0.23 in rough lemon, and 0.11 in 'Valencia') making SPAD assessments of questionable value in comparing CLas titers between genotypes.

Tree growth. Tree response to illumination treatments, as measured by change in trunk diameter, varied between genotypes. Both 'Kuharske' citrange and rough lemon displayed greater growth in the constant illumination condition (Fig. 1), but following removal to the greenhouse in Dec.2012, growth rates were very similar between treatments, essentially maintaining differences that 


\section{Kuharske citrange}

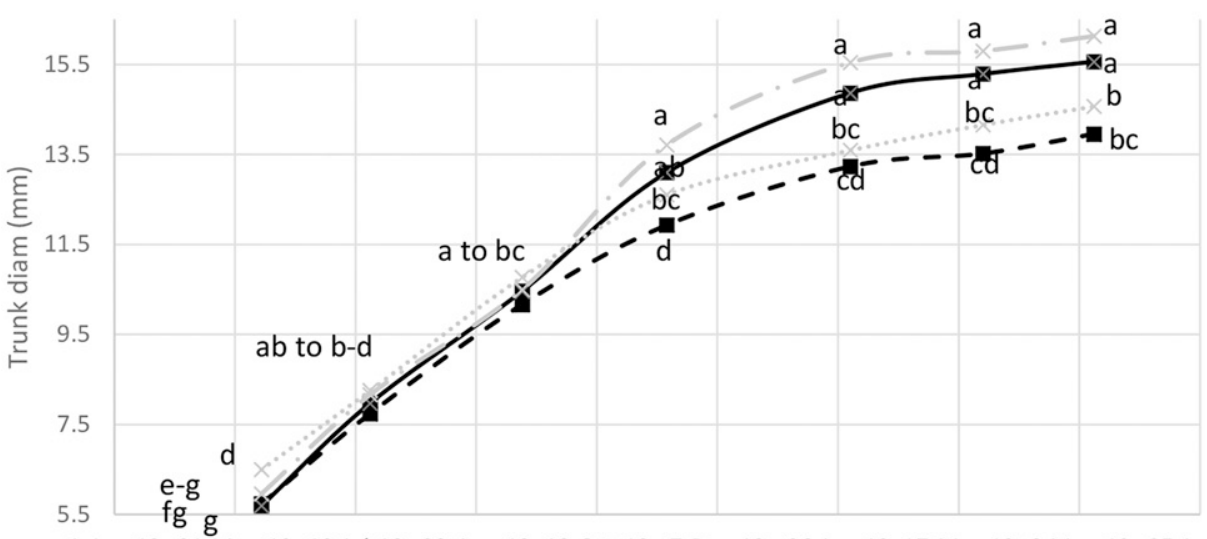

1-Apr-12 21-May-12 10-Jul-12 29-Aug-12 18-Oct-12 7-Dec-12 26-Jan-13 17-Mar-13 6-May-13 25-Jun-13

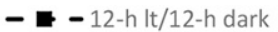

$\rightarrow-24$-h light $\quad \cdots \cdot \cdots \cdot \cdots \cdot 12$-h /12-h plus score $\quad \longrightarrow \times \cdot-24$-h light plus score

\section{Rough Lemon}

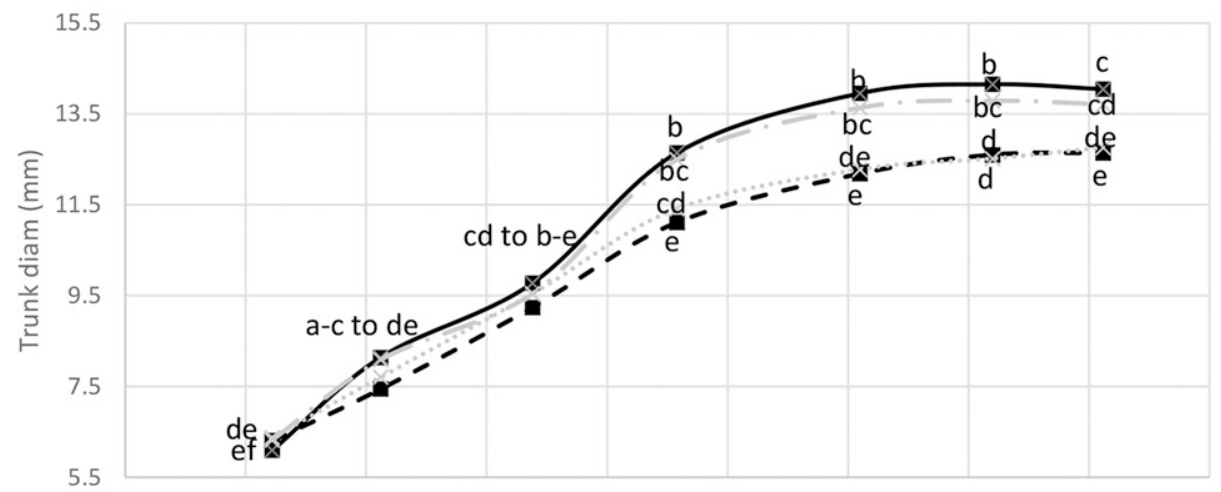

1-Apr-12 21-May-12 10-Jul-12 29-Aug-12 18-Oct-12 7-Dec-12 26-Jan-13 17-Mar-13 6-May-13 25-Jun-13

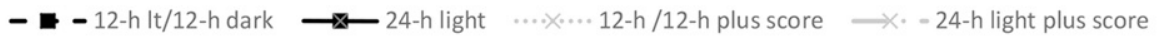

\section{Valencia sweet orange}

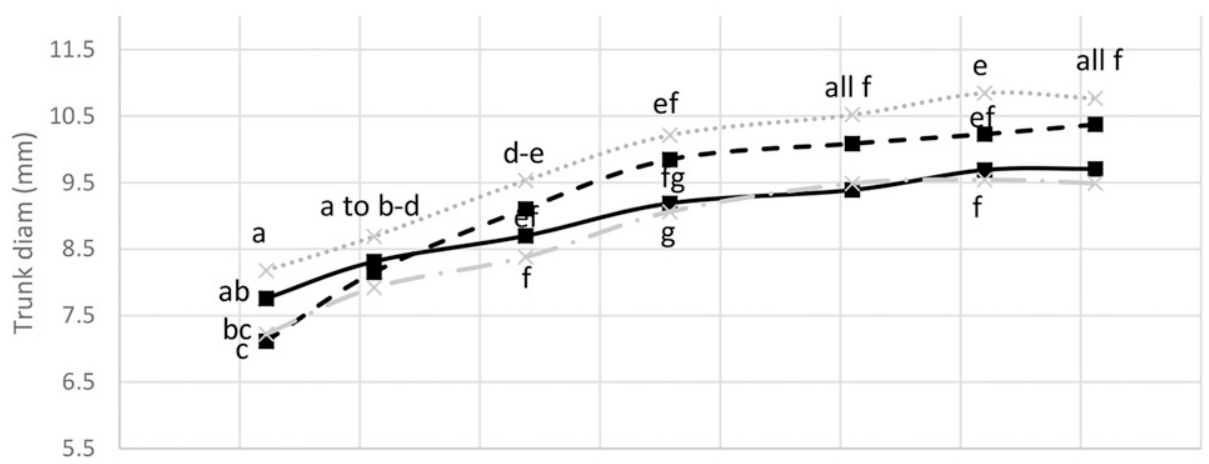

1-Apr-12 21-May-12 10-Jul-12 29-Aug-12 18-Oct-12 7-Dec-12 26-Jan-13 17-Mar-13 6-May-13 25-Jun-13

- E - 12-h It/12-h dark

Fig. 1. Data shown are trunk diameters at $5 \mathrm{~cm}$ above the soil. Sixty trees of each of three citrus genotypes ('Kuharske', previously shown to be huanglongbing (HLB) resistant; rough lemon, previously shown to be HLB tolerant; and 'Valencia', HLB susceptible) were bud grafted using two Candidatus Liberibacter asiaticus (CLas)-infected buds per tree on 26 Mar. 2012 and were placed in controlled growth rooms (one $12 \mathrm{~h}$ light: $12 \mathrm{~h}$ dark and one constant light, both rooms were $16 \mathrm{~h}$ at $30{ }^{\circ} \mathrm{C}$ and $8 \mathrm{~h}$ at $25^{\circ} \mathrm{C}$ ) on 4 June 2012 . Ten trees of each genotype in each growth room were scored with a knife on 18, July 2012 and the scoring was repeated on the same trees at the same scoring wounds on 30 Aug. 2012. Trees were removed from growth rooms on 12 Dec. 2012 and subsequently grown in a greenhouse. At each date and across all three genotypes means followed by the same letter are not significantly different at $P \leq 0.05$.

developed in the growth room. 'Valencia' sweet orange displayed differences between treatments in mean tree diameter from the first measurements, indicating our visual observation of uniformity was inaccurate when trees were assigned to treatments. The 'Valencia' trees exposed to $12 \mathrm{~h}$ light: $12 \mathrm{~h}$ dark, combined with scoring, were the largest throughout the study, even preceding scoring. The rate of growth, however, was different between the treatments with the trees exposed to continuous light growing more slowly 
than the trees with $12 \mathrm{~h}$ light: $12 \mathrm{~h}$ dark. As in the other two genotypes, following removal to the greenhouse, growth rates were very similar between treatments. Scoring treatments had no observed effect on tree growth.

$H L B$ tolerance. Recent reports from Florida have documented tolerance to HLB in a number of genotypes including rough lemon that was shown to display less phloem disruption than the highly susceptible sweet orange (Fan et al., 2012). Several other genotypes with citron in the pedigree have also been documented to display markedly greater growth and canopy health than most HLB-affected accessions in the genus Citrus (G.P. Miles et al., unpublished data). It was noted that HLB tolerance in mandarin hybrids was not associated with delayed symptoms or lower CLas titers than highly HLB-susceptible sweet orange and grapefruit (Stover et al., 2016b). Response of HLB-tolerant rough lemon in this study was generally similar to 'Valencia' in CLas titer (Table 1), but rough lemon displayed markedly greater growth than 'Valencia' (Fig. 1), which is consistent with HLB tolerance.

\section{Conclusions}

Experiments were conducted to assess whether continuous illumination or trunk scoring might permit more rapid screening for HLB tolerance/resistance. Three genotypes were compared, 'Kuharske', previously shown to be HLB resistant; rough lemon, previously shown to be HLB tolerant; and 'Valencia', highly HLB susceptible. At the earliest time point, 6 months after inoculation (Sept. 2012), CLas titer was greater in 'Valencia' than 'Kuharske' averaged across all treatments, but for individual treatments this difference was observed only with $12 \mathrm{~h}$ light: $12 \mathrm{~h}$ dark plus scoring and continuous illumination without scoring. Although there were significant effects of scoring, since they were inconsistent, there is no clear value in using this practice to accelerate HLB screening. With continuous lighting, marked differences were only observed between genotypes after removal from continuous lighting (after Dec. 2012), with 'Valencia' distinguished from 'Kuharske' in each treatment combination. However, before this, at 8 months after inoculation (Nov. 2012), continuous illumination accelerated CLas titer but all three genotypes had titers which were not statistically different from each other within each treatment. Therefore, rather than facilitating rapid differentiation between
HLB-susceptible and HLB-resistant genotypes, exposure to continuous illumination accelerated pathogen development but did not reveal differences in susceptibility.

\section{Literature Cited}

Albrecht, U. and K.D. Bowman. 2008. Gene expression in Citrus sinensis (L.) Osbeck following infection with the bacterial pathogen Candidatus Liberibacter asiaticus causing Huanglongbing in Florida. Plant Sci. 175:291306.

Bhagabati, K.N. 1993. Survey of greening disease of mandarin orange in the northeastern states of India, p. 441-442. In: P. Moreno, J.V. da Graca, and L.W. Timmer (eds.). Proc. 12th Conference of the International Organization of Citrus Virologists, University of California, Riverside.

Bové, J.M. 2006. Huanglongbing: A destructive, newly-emerging, century-old disease of citrus. J. Plant Pathol. 88:7-37.

Cheema, S.S., S.P. Kapur, and J.S. Chohan. 1982. Evaluation of rough lemon strains and other rootstocks against greening-disease of citrus. Sci. Hort. 18:71-75.

Dutt, M., G. Barthe, M. Irey, and J. Grosser. 2015. Transgenic citrus expressing an Arabidopsis NPR1 gene exhibit enhanced resistance against huanglongbing (HLB; Citrus Greening). PLoS One 11(1):E0147657.

Fan, J., C. Chen, Q. Yu, A. Khalaf, D.S. Achor, R.H. Brlansky, G.A. Moore, Z.-G. Li, and F.G. Gmitter, Jr. 2012. Comparative transcriptional and anatomical analyses of tolerant rough lemon and susceptible sweet orange in response to 'Candidatus Liberibacter asiaticus' infection. Mol. Plant Microbe Interact. 25:13961407.

Folimonova, S.Y., C.J. Robertson, S.M. Garnsey, S. Gowda, and W.O. Dawson. 2009. Examination of the responses of different genotypes of Citrus to huanglongbing (Citrus greening) under different conditions. Phytopathology 99:1346-1354

Fraser, L.R. and D. Singh. 1970. Reaction of Indian citrus varieties to greening virus. 1 st Intl. Citrus Symp., Riverside 1968. 1:365-366.

Gottwald, T.R. 2010. Current epidemiological understanding of citrus huanglongbing. Annu. Rev. Phytopathol. 48:119-139.

Halbert, S.E. and K.L. Manjunath. 2004. Asian citrus psyllids (Sternorrhyncha: Psyllidae) and greening disease of citrus: A literature review and assessment of risk in Florida. Fla. Entomol $87: 330-353$.

Hao, G., E. Stover, and G. Gupta. 2016. Overexpression of a modified plant thionin enhances disease resistance to citrus canker and huanglongbing (HLB). Front. Plant Sci. 7:1078.

Koizumi, M., M. Prommintara, G. Linwattana, and T. Kaisuwan. 1997. Epidemiological aspects of citrus huanglongbing (greening) disease in Thailand. Japan Agr. Res. Qrtly. 31:205-211.

Lange, J.H. de, A.P. Vincent, and M. Nel. 1985. Breeding for resistance to greening disease in citrus. Citrus Subtrop. Fruit J. 614:6-9.

Miyakawa, T. 1980. Experimentally-induced symptoms and host range of citrus likubin (greening disease). Ann. Phytopath. Soc. Japan 46:224-230.

Miyakawa, T. and Z.X. Yuan. 1990. Citrus host range of greening disease, p. 118-121. In: B. Aubert, S. Tontyaporn, and D. Buangsuwon (eds.). Proc. 4th International Asia Pacific Conference on Citrus Rehabilitation. FAOUNDP.

Nariani, T.K. 1981. Integrated approach to control citrus greening disease in India. Proc. Intl. Soc. Citricult. 1:471-472.

Ramadugu, C., M. Keremane, S. Halbert, Y.-P. Duan, M.L. Roose, E. Stover, and R. Lee. 2016 Long term field evaluation reveals HLB resistance in Citrus relatives. Phytopathology 9:1858-1869.

Schwarz, R.E., L.C. Knorr, and M. Prommintara. 1973. Presence of Citrus greening and its psylla vector in Thailand. Plant Protection Bull. FAO 21:132-138.

Sharma, B.D., D.K. Hore, and S.G. Gupta. 2004. Genetic resources of Citrus of north-eastern India and their potential use. Genet. Resources Crop Evol. 51:411-418.

Shokrollah, H., T.L. Abdullah, K. Sijam, S.N.A. Abdullah, and N.A.P. Abdullah. 2009. Differential reaction of citrus species in Malaysia to huanglongbing (HLB) disease using grafting method. Amer. J. Agr. Biol. Sci. 4:32-38.

Singerman, A. and P. Useche. 2015. Impact of citrus greening on citrus operations in Florida. Dec. 2015. <http://www.crec.ifas.ufl.edu/extension/ economics/pdf/Impact\%20Citrus\%20Greening $\% 20$ web.pdf $>$.

Stover, E., G. McCollum, J. Ramos, and R.G. Shatters, Jr. 2015. Growth, health and Liberibacter asiaticus titer in diverse citrus scions on mandarin vs. trifoliate hybrid rootstocks in a field planting with severe huanglongbing. Proc Fla. State Hort. Soc. 127:53-59.

Stover, E., D.G. Hall, R.G. Shatters, Jr., and G.A. Moore. 2016a. Influence of citrus source and test genotypes on inoculations with Candidatus Liberibacter asiaticus. HortScience 51:805809.

Stover, E., S. Inch, M. Richardson, and D.G. Hall. 2016b. Conventional citrus of some scion/ rootstock combinations show field tolerance under severe huanglongbing disease pressure. HortScience 51:127-132.

Western Farm Press. 2016. Huanglongbing (citrus greening) continues its southern California spread. Dec. 2015. <http://westernfarmpress.com/orchardcrops/huanglongbing-citrus-greening-continuesits-southern-california-spread $>$. 